\title{
Critical Data Literacy in Immersive Digital Spaces
}

\author{
Dario Rodighiero ${ }^{1}$, Eveline Wandl-Vogt ${ }^{1234}$, Elian Carsenat ${ }^{5}$, \\ Jules Döring ${ }^{6}$, Oliver Elias ${ }^{6}$, Michela Fragner ${ }^{7}$, Stepha Farkashazy ${ }^{7}$ \\ ${ }^{1}$ metaLAB, Harvard University \\ ${ }^{2}$ exploration space (at) Austrian Academy of Sciences \\ ${ }^{3}$ Ars Electronica Research Institute knowledge for humanity \\ ${ }^{4}$ Embassy of Uzupis knowledge for humanity \\ ${ }^{5} \mathrm{NamSor}$ \\ ${ }^{6}$ Garamantis \\ ${ }^{7}$ Ars Electronica Solutions
}

Philippe Starck's Juicy Salif is a good example of how bad design can be useful: the citrus reamer works poorly indeed, squirting lemon juice all over the kitchen in the hope of extracting the juice. However, Juicy Salif has the great capacity of being a catalyst of conversations around the tension between form and function (Heskett [2002] 2005). This short text is about the opportunity of using museum spaces to foster public conversation through the use of data in immersive, digital environments. Such as Philippe Starck's lemon squeezer, the idea is to design data-driven digital installations to visually stimulate a critical dialogue on a specific subject, developing what is called critical data literacy, i.e. the ability to read information through the graphic language of data visualizations. 
The 3D Cartography of COVID-19 Research (Ars Electronica 2021) is a participatory project that was presented last year at Ars Electronica, a festival of new media art based in Linz, Austria (Jandsl and Stocker 2021). The project takes the form of a three-dimensional data visualization through which the invisible work of scientists on the current pandemic is revealed. The visualization shows more than 600,000 scientific articles, extracted from the Covid-19 open research dataset (Wang et al. 2020). The articles are organized in the two-dimensional space by applying a measure of language similarity (Salton, Wong, and Yang 1975) to a system of dimensionality reduction (McInnes, Healy, and Melville 2018). The bi-dimensional space is successively translated into the three dimensions by stretching the publication dates on the $\mathrm{z}$-axis, giving rise to a temporal representation of the scientific practice.

The data visualization was specifically designed for the Deep Space 8K, which is an immersive digital theater part of the Ars Electronica Center, a museum aimed to disclose the impact of technological developments on society. The Deep Space $8 \mathrm{~K}$ is a presentation room with two projected screens measuring $16 \times 9$ meters, respectively positioned on the wall and on the floor to create an immersive experience. In such a space, performers and visitors share the same environment that reduces the distance between the stage and the seats, making this relationship closer and more intimate.

The 3D Cartography was presented to a limited audience composed of 40 spectators due to COVID 19 security restrictions. The presentation was articulated in two phases: the initial phase was intended to present the data visualization and speakers' insights to the audience, while in the later phase the spectators were invited to intervene and browse the information space through a gamepad. If the former part condensed one year of conversations between the project's authors, the latter extended the perception of the data visualization by introducing spectators' points of view through question-and-answer interaction.

The shared space of the Deep Space 8K favored spectators' involvement with a less marked division between stage and audience. In addition, the immersive dimension transformed the data visualization not only into an object to stare at but also into a sphere (Sloterdijk [2005] 2013) which both presenters and the audience are part of. Paraphrasing Bruno Latour's recent studies, one could say that the spectator's standpoint is not external but internal to the subject of matter (Latour and Weibel 2020). This experience shows how museum spaces can be designed for hosting data and fostering a confrontation between experts and visitors. The 3D Cartography of COVID-19 Research was intended to develop a critical approach to design exhibition spaces and make digital information available to a larger audience.

This project was possible thanks to the generous support of DARIAH through the grant schema Theme Call in Arts, Humanities, and COVID-19 (DARIAH 2020). The photographs in this article have been provided by Ars Electronica, My Trinh Müller-Gardiner. 


\section{Short Bibliography}

- Ars Electronica. 2021. “3D Cartography of COVID-19 Research.” Ars Electronica, a New Digital Deal. September 9, 2021.

https://ars.electronica.art/newdigitaldeal/en/cartography-covid-19-research/.

- DARIAH. 2020. “Theme Call 2020/2021: Meet the Winning Projects.” December 10, 2020.

https://www.dariah.eu/2020/12/10/dariah-theme-call-2020-2021-meet-the-winning-p rojects/.

- Heskett, John. (2002) 2005. Design: A Very Short Introduction. Very Short Introductions. Oxford: Oxford University Press.

- Jandsl, Markus, and Gerfried Stocker, eds. 2021. Ars Electronica 2021. Festival for Art, Technology and Society. Berlin: Hatje Cantz Verlag.

- Latour, Bruno, and Peter Weibel, eds. 2020. Critical Zones: Observatories for Earthly Politics. Cambridge, MA: MIT Press.

- McInnes, Leland, John Healy, and James Melville. 2018. “UMAP: Uniform Manifold Approximation and Projection for Dimension Reduction." ArXiv.Org stat.ML

(February). https://arxiv.org/pdf/1802.03426.pdf.

- Salton, G, A Wong, and C S Yang. 1975. “A Vector Space Model for Automatic Indexing." Communications of the ACM 18 (11): 613-20. https://doi.org/10/fw8vv8.

- Sloterdijk, Peter. (2005) 2013. In the World Interior of Capital: For a Philosophical Theory of Globalization. Translated by Wieland Hoban. First English edition. Cambridge, UK; Malden, MA: Polity.

- Wang, Lucy Lu, Kyle Lo, Yoganand Chandrasekhar, Russell Reas, Jiangjiang Yang, Doug Burdick, Darrin Eide, et al. 2020. "CORD-19: The COVID-19 Open Research Dataset." In Proceedings of the Workshop on NLP for COVID-19 at ACL 2020. Association for Computational Linguistics. https://arxiv.org/abs/2004.10706. 

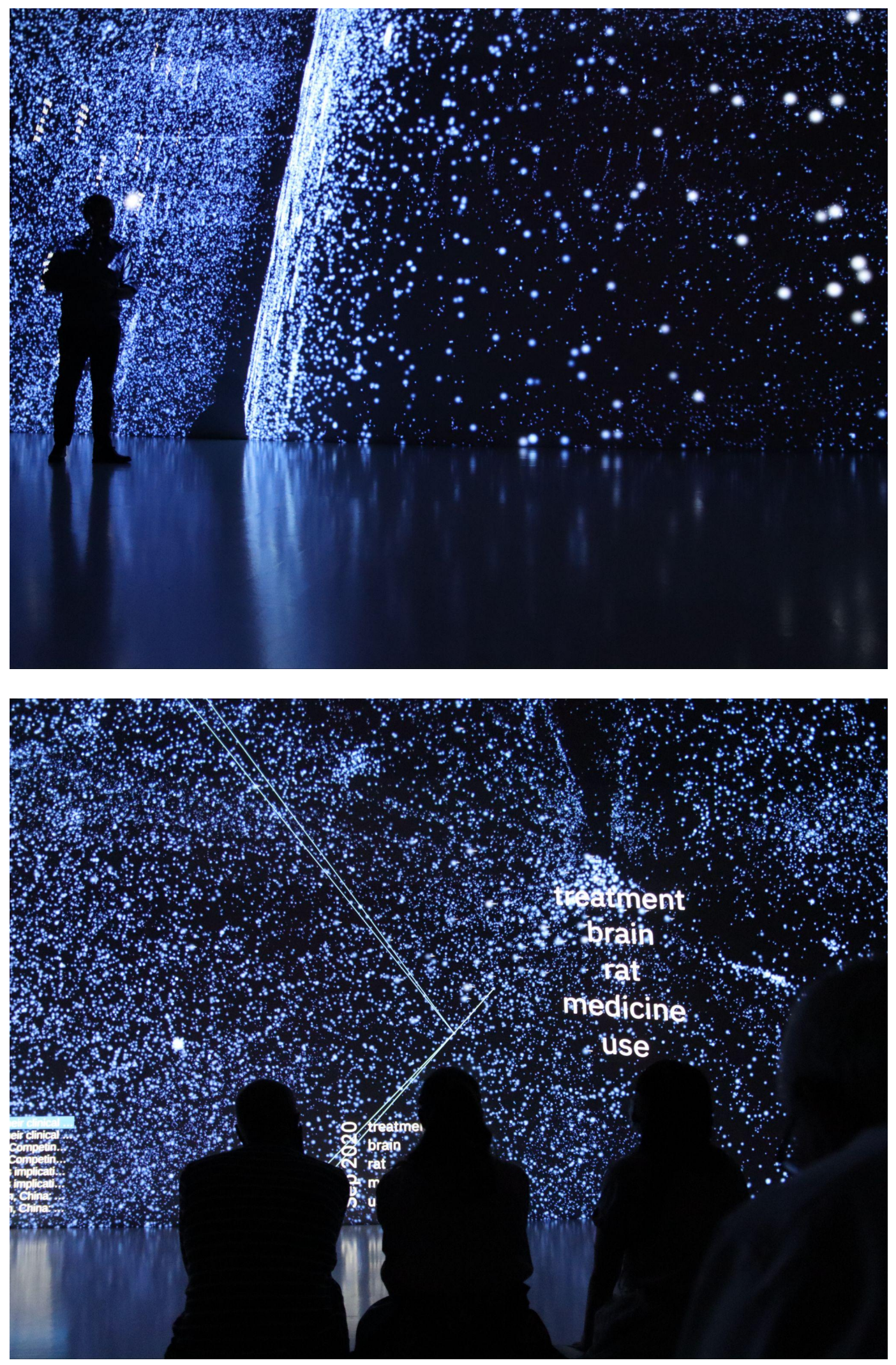

Foto Credits: Ars Electronica Solutions / My Trinh Müller-Gardiner 